\title{
LTE Downlink Performance of Cigar-Shaped Highways Microcells with and Without Small Scale Fading
}

\author{
Bazil Taha Ahmed* \\ Universidad Autónoma de Madrid, Madrid, 28049, Spain
}

*Corresponding Author: Bazil Taha Ahmed, Universidad Autónoma de Madrid, Madrid, 28049, Spain

\begin{abstract}
In this paper, the performance of the downlink of the LTE systems for cigar-shaped microcells at highways is studied. The two-slope propagation loss model is used to calculate the signal to interference plus noise ratio taking into account the expected value and the variance of the cochannel and adjacent channel interference. Also, the effect of the inter-carriers interference due to the user movement is taken into account. A model of ten cigar-shaped microcells is used in the LTE performance analysis. For the frequency band of $2.6 \mathrm{GHz}$ with a $10 \mathrm{MHz}$ bandwidth, the base station transmitted power should be $2 \mathrm{~W}$ to get a sector range of $1356 \mathrm{~m}$ meanwhile it should be $3.1 \mathrm{~W}$ to get $1500 \mathrm{~m}$ sector range. For the $800 \mathrm{MHz}$ frequency band, maximum range of 2909 can be got with a transmitted power $4 \mathrm{~W}$ when the break point distance $R_{b}$ is maintained at $250 \mathrm{~m}$. With a frequency reuse of 2, a sector mean bit rate up to $41.65 \mathrm{Mbps}$ can be got with a $10 \mathrm{MHz}$ bandwidth. Small scale fading affects the SINR of the LTE user and consequently the downlink bit rate.
\end{abstract}

Keywords: LTE, cigar-shaped microcell, cochannel interference, intercarrier interference, downlink bit rate, adjacent channel interference.

\section{INTRODUCTION}

LTE (Long-Term Evolution) is a standard for wireless communication of high-speed data for mobile phones and data terminals. Its downlink bit rate that can reach 100 Mbps using 64QAM modulation with $20 \mathrm{MHz}$ bandwidth.

Based on the GSM/EDGE and UMTS/HSPA network technologies, capacity and speed have been increased using a different radio interface together with core network improvements [1] [2]. The standard is developed by the 3GPP (3rd Generation Partnership Project) and is specified in its Release 8 document series, with minor enhancements described in Release 9.

Long Term Evolution (LTE) radio access technology is the fastest developing system in mobile communication. In mid-2012, LTE networks covered 455 million people in the world [3], and by 2018 , it is expected to cover approximately $57 \%$ of the world's population. By 2018 , the number of LTE base stations (BSs) is expected to increase to 2.43 million to achieve the population coverage target, which is expected to reach 1.3 billion LTE subscribers [4]. South Korea has a LTE penetration of $97 \%$. Only multi-band phones will be able to use the different LTE frequencies that are used in different countries.

LTE as specified in the $3 \mathrm{GPP}$ Release 8 and 9 document series is marketed as a $4 \mathrm{G}$ wireless service in spite of their unsatisfaction of the technical requirements the 3GPP consortium has adopted for its new standard generation, and which were originally set forth by the ITU-R organization in its IMTAdvanced specification.

LTE uses OFDM in the downlink (DL) with a time division duplex (TDD) frame structure of duration $5 \mathrm{~ms}$ shared between the UL and DL. Adaptive modulation (QPSK, 16 QAM and 64 QAM) and coding is used in the downlink of the LTE system. In uplink, LTE uses the single-carrier frequency division multiple access (SC-FDMA).

Several papers have dealt with the capacity of LTE systems. In [2], the performance of the LTE downlink is investigated using 6 taps typical urban channel. In [5], the peak throughput for TDD and FDD 4 G LTE systems is calculated. For LTE system with 4*4 MIMO (Multi Input-Multi Output), using $20 \mathrm{MHz}$ bandwidth, the peak throughput reaches $403.2 \mathrm{Mbps}$.

International Journal of Innovative Research in Electronics and Communications (IJIREC) Page $\mid 9$ 
Work [6] shows a more comprehensive investigation of the maximum data throughput under different conditions and scenarios. The performance study includes TDD and FDD operational modes for uplink and downlink transmissions in different antenna diversity schemes, data modulation, and code rates. Results show that LTE (3GPP Release 8) supports downlink throughputs of up to $300 \mathrm{Mbps}$ and for the uplink a throughput of up to 75 Mbps.

In this study, each cigar-shaped microcell has two sectors and a directional antenna is used in each one of them and that the typical separation between two successive base stations is 1.5 to $2.5 \mathrm{Km}$.

To the author's best knowledge, there isn't any literature that deals with the LTE in highways microcells.

The aim of this work is to investigate the performance (bit rate and range) of the LTE in highway's cigar shaped microcells.

The rest of the paper has been organized as follows. In Section 2, the propagation model used in the calculation of the interference statistics is given. In Section 3, the interference statistics (mean value and variance) are analyzed. Numerical results are presented in Section 4. Finally, in Section 5 conclusions are drawn.

\section{Propagation Loss Model}

In [7], it has been shown that the two slope model is the best propagation model that can be used to calculate the propagation loss in highways. We have used it in our previous work [8-12] to analyze the performance of the WCDMA systems. Thus, the two-slope propagation model with lognormal shadowing is used in the analysis of the LTE performance.

The two slope propagation model consists of a constant value which represents the propagation loss at a very short distance such as $1 \mathrm{~m}$, a distance dependent term and extra terms representing shadowing, small scale fading and extra losses.

The exponent of the propagation is assumed to be $n_{1}$ until the break point (at a distance $R_{b}$ ) and then it changes to higher value of $\mathrm{n}_{2}$. Small scale fading (if exists) is presented by Rice fading. In this way the path loss between the basestation and the mobile user at a distance $r$ from it is given by:

$$
\begin{array}{ll}
L_{p}(d B)=L_{R b}+10 n_{1} \log _{10}\left(\frac{r}{R_{b}}\right)+L_{g}+L_{\text {extra }}+\xi_{1}+\text { Rice } & \mathrm{r} \leq \mathrm{R}_{\mathrm{b}} \\
L_{p}(d B)=L_{R b}+10 n_{2} \log _{10}\left(\frac{r}{R_{b}}\right)+L_{g}+L_{\text {extra }}+\xi_{2}+\text { Rice } & \mathrm{r}>\mathrm{R}_{\mathrm{b}}
\end{array}
$$

where $\mathrm{L}_{\mathrm{g}}$ is the car window penetration loss, $\mathrm{L}_{\text {extra }}$ is an extra loss that depends on the direction of the arrival of the LTE signal $(0 \mathrm{~dB}$ if the signal is received from the front side of the car and $10 \mathrm{~dB}$ if the signal is received from the back side of the car), $\mathrm{r}$ is the distance between the LTE basestation base and the mobile user , $\xi 1$ and $\xi 2$ are Gaussian random variables of zero-mean and a standard deviation of $\sigma_{1}$ and $\sigma_{2}$ respectively representing what is called the shadowing effect (in reality it is path loss deviation from the average value).

Without taking into account shadowing and small scale fading, $\mathrm{L}_{\mathrm{b}}$ (propagation loss at the break point) is given as:

$$
L_{b}(d B)=20 \log _{10}\left(\frac{4 \pi}{\lambda}\right)+10 n_{1} \log _{10}\left(R_{b}\right)
$$

The break-point distance $R_{b}$, where propagation exponent changes from $n_{1}$ to $n_{2}$ is given by [13]:

$$
R_{b}=\frac{4 h_{b} h_{m}}{\lambda}
$$

Where

- $\mathrm{h}_{\mathrm{b}}$ is the base station antenna height in $\mathrm{m}$ used to be 6 to 10 meters,

- $\mathrm{h}_{\mathrm{m}}$ is the mobile antenna height in $\mathrm{m}$ that depends on the car in which users travel,

International Journal of Innovative Research in Electronics and Communications (IJIREC) $\quad$ Page | 10 
- $\lambda$ is the operating wavelength in $\mathrm{m}$.

Typical values of the above mentioned parameters are [8-12]:

- $\mathrm{n}_{1}=2.0$,

- $\mathrm{n}_{2}=4.0$,

- $\sigma_{1}=3.0 \mathrm{~dB}$,

- $\sigma_{2}=6.0 \mathrm{~dB}$,

- $\mathrm{R}_{\mathrm{b}}=200$ to $400 \mathrm{~m}$ for the $2.6 \mathrm{GHz}$ band,

- $\mathrm{L}_{\mathrm{g}}=3 \mathrm{~dB}$ for $2.6 \mathrm{GHz}$ band,

- $\mathrm{K}_{\text {Rice }}=5$ to 10 .

\section{DOWNLINK INTERFERENCE ANALYSIS}

We will calculate interference in the same way that has been given in our previous work [8-12] modifying some equations to apply it for our studied case. Here the cochannel interference and the adjacent channel interference will be calculated.

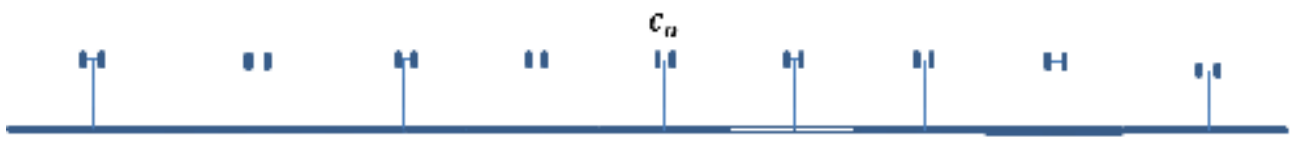

A- Cigar-shaped base stations model.

Left sector coverage

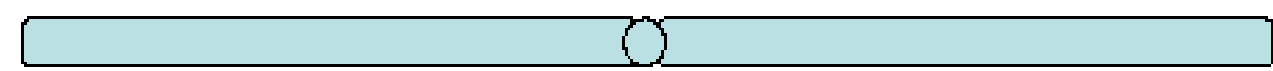

B- Coverage diagram of the two directional antennas used en each base station.

Right sector coverage

Fig1. Base stations model and the base station coverage diagram.

Using the two-slope model of propagation mentioned in Section 2, we will calculate the cochannel and adjacent channel interference statistics (mean value and variance) to find the LTE maximum sector range and bit rate. Fig. 1 shows the configuration of the base stations model accounted for in the analysis and the sector coverage of each one of the two sectors of the microcell. The base stations are assumed to be regularly spaced every $2 \mathrm{R}$ (in practice it is impossible to fulfil this assumption). The LTE performance will be studied considering the right sector of the base station $\mathrm{C}_{0}$. If the user $\mathrm{i}$ is at a distance $r_{i o}$ from the base station under study $\left(C_{0}\right)$ and at a distance $r_{i d}$ from the interfering base station $d$ as shown in Fig. 2. Then the ratio of the interference signal ratio given by a loss like term $\mathrm{L}\left(\mathrm{r}_{\mathrm{id}}, \mathrm{r}_{\mathrm{io}}\right)$ due to the distance only is given as:

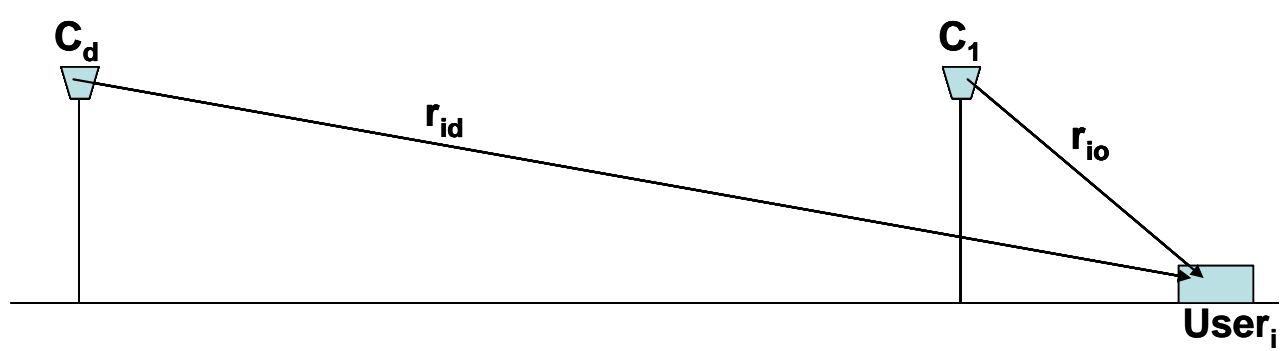

Fig2. Schematic diagram of base stations and mobiles for highway microcells scenario.

- For the impractical case when $\left(r_{i d}\right.$ and $\left.r_{i o} \leq R_{b}\right)$, then the loss like term $L\left(r_{i d}, r_{i o}\right)$ is:

$L\left(r_{i d}, r_{i o}\right)=\left(\frac{r_{i o}}{r_{i d}}\right)^{n_{1}}$

- When $r_{i d}>R_{b}$ and $r_{i o} \leq R_{b}$ then $L\left(r_{i d}, r_{i o}\right)$ is given as:

International Journal of Innovative Research in Electronics and Communications (IJIREC) 
$L\left(r_{i d}, r_{i o}\right)=\left(\frac{r_{i o}}{R_{b}}\right)^{n_{1}}\left(\frac{R_{b}}{r_{i d}}\right)^{n_{2}}$

- When $\left(r_{\text {id }}\right.$ and $\left.r_{i o}>R_{b}\right)$ then $L\left(r_{i d}, r_{i o}\right)$ is:

$L\left(r_{i d}, r_{i o}\right)=\left(\frac{r_{i o}}{r_{i d}}\right)^{n_{2}}$

Taking into account the effect of shadowing, the ratio of the interference signal $\mathrm{L}_{\text {shd }}\left(\mathrm{r}_{\mathrm{id}}, \mathrm{r}_{\mathrm{io}}\right)$ is calculated as:

$$
L_{s h d}\left(r_{i d}, r_{i o}\right)=10^{\left(\xi_{i d}-\xi_{i o}\right) / 10} L\left(r_{i d}, r_{i o}\right)
$$

Where $\xi_{\text {id }}$ and $\xi_{\text {im }}$ are given as

- When $\left(\mathrm{r}_{\mathrm{id}}\right.$ and $\left.\mathrm{r}_{\mathrm{io}} \leq \mathrm{R}_{\mathrm{b}}\right)$, $\xi_{\mathrm{id}}=\xi_{1}$ and $\xi_{\mathrm{io}}=\xi_{1}$.

- If $\mathrm{r}_{\mathrm{id}}>\mathrm{R}_{\mathrm{b}}$ and $\mathrm{r}_{\mathrm{io}} \leq \mathrm{R}_{\mathrm{b}}$ then $\xi_{\mathrm{id}}=\xi_{2}$ and $\xi_{\mathrm{io}}=\xi_{1}$.

- When $\left(\mathrm{r}_{\mathrm{id}}\right.$ and $\left.\mathrm{r}_{\mathrm{io}}>\mathrm{R}_{\mathrm{b}}\right)$, $\xi_{\mathrm{id}}=\xi_{2}$ and $\xi_{\mathrm{io}}=\xi_{2}$.

The received power $\mathrm{P}_{\mathrm{rx}}$ of the desired signal of the LTE user under study is given by:

$P_{r x}=P_{t x} 10^{\left(-L_{o r}(d B)+G_{T X}(d B)+G_{R X}(d B)\right) / 10}$

where $\mathrm{P}_{\mathrm{tx}}$ is the transmitted power of the LTE basestation toward the LTE mobile user, $\mathrm{L}_{\mathrm{or}}$ is the path loss (measured in $\mathrm{dB}$ ) between the basestation under study and the user at location $r, \mathrm{G}_{\mathrm{Tx}}$ is the base station antenna gain measured in $\mathrm{dB}$ and $\mathrm{G}_{\mathrm{Rx}}$ is the mobile antenna gain assumed to be $0 \mathrm{~dB}$.

Equation (9) representing the desired signal received power can be rewritten as:

$P_{r x}=\kappa P_{t x}$

where $\kappa$ is the propagation gain of the desired signal given as:

$\kappa=10^{\left(-L_{o r}(d B)+G_{T X}(d B)+G_{R X}(d B)\right) / 10}$

To calculate the received power of the desired signal, the propagation loss $\mathrm{L}_{\text {or }}$ of this signal should be calculated. Here the effect of both the distance and shadowing is included. For a given availability of $\alpha, \mathrm{L}_{\text {or }}$ is given as:

$$
\begin{array}{ll}
L_{o r}(d B)=L_{R b}+10 n_{1} \log _{10}\left(\frac{r}{R_{b}}\right)+L_{g}+L_{\text {extra }}+\sigma_{1} Q^{-1}(\alpha)+\text { Rice } & \mathrm{r} \leq \mathrm{R}_{\mathrm{b}} \\
L_{o r}(d B)=L_{R b}+10 n_{2} \log _{10}\left(\frac{r}{R_{b}}\right)+L_{g}+L_{\text {extra }}+\sigma_{2} Q^{-1}(\alpha)+\text { Rice } & \mathrm{r}>\mathrm{R}_{\mathrm{b}}
\end{array}
$$

Where $\mathrm{Q}^{-1}$ ( ) is the inverse of the Gaussian Q function with a value of 2.05 for an availability of $98 \%$ while it is 2.33 for availability of $99 \%$.

The expected value of the cochannel interference power due to $\mathrm{N}$ cochannel LTE base stations transmitting their interfering signal through the main lobe of the antenna and $\mathrm{M}$ cochannel LTE base stations transmitting their interfering signal through the back lobe of the antenna is given by:

$$
\begin{aligned}
E\left[I_{c c}\right] & =\kappa \sum_{d \in N} P_{t x, d} e^{\left(\beta^{2} \sigma^{2} / 2\right)} L\left(r_{i d}, r_{i o}\right) Q\left[\beta \sigma+\frac{10 \log _{10}\left\{L\left(r_{i d}, r_{i o}\right)\right\}}{\sigma}\right] U_{d} \\
& +\kappa \text { Bll } \sum_{d \in M} P_{t x, d} e^{\left(\beta^{2} \sigma^{2} / 2\right)} L\left(r_{i d}, r_{i o}\right) Q\left[\beta \sigma+\frac{10 \log _{10}\left\{B l l * L\left(r_{i d}, r_{i o}\right)\right\}}{\sigma}\right] U_{d}
\end{aligned}
$$

Where

- $\beta=(\ln 10) / 10$,

- $\sigma$ is standard deviation of shadowing term $\left(\xi_{\mathrm{id}}-\xi_{\mathrm{io}}\right)$.

International Journal of Innovative Research in Electronics and Communications (IJIREC) 
- $\mathrm{Q}$ is the Gaussian $\mathrm{Q}$ function given by:

$Q(x)=\frac{1}{\sqrt{2 \pi}} \int_{x}^{\infty} e^{-y^{2} / 2} d y$

- $\mathrm{U}_{\mathrm{d}}$ is a number equal to 1 if the base station $\mathrm{d}$ is on line of sight (LOS) with the user and 0 for the non-line of sight (NLOS) case.

- Bll is the back lobe normalized gain of the transmitting antenna with a typical value of $-25 \mathrm{~dB}$ to $30 \mathrm{~dB}$.

The variance of shadowing $\sigma^{2}$ that depends on the location of the point under study is given as:

- When $\left(r_{i d}\right.$ and $\left.r_{i o} \leq R_{b}\right), \sigma_{i d}=\sigma_{1}$, also $\sigma_{i o}=\sigma_{1}$ then

$\sigma^{2}=2\left(1-C_{d o}\right) \sigma_{1}^{2}$

Where $\mathrm{C}_{\mathrm{do}}$ is the inter-sites correlation coefficient of the shadowing parameters $\xi_{\text {id }}$ and $\xi_{\mathrm{io}}$. It has a worst case value of 0 and a best case value of 1 .

- If $\mathrm{r}_{\mathrm{id}}>\mathrm{R}_{\mathrm{b}}$ and $\mathrm{r}_{\mathrm{id}} \leq \mathrm{R}_{\mathrm{b}}$ then the value of $\sigma^{2}$ is given by:

$\sigma^{2}=\left(\sigma_{1}-\sigma_{2}\right)^{2}+2\left(1-C_{d o}\right) \sigma_{1} \sigma_{2}$

- When $\left(r_{\text {id }}\right.$ and $\left.r_{\text {io }}>R_{b}\right), \sigma_{\text {id }}=\sigma_{2}$, also $\sigma_{\text {io }}=\sigma_{2}$ then

$\sigma^{2}=2\left(1-C_{d o}\right) \sigma_{2}^{2}$

Let us now calculate the interference variance.

The variance of the cochannel interference power is given by:

$$
\begin{aligned}
\operatorname{var}\left[I_{c c}\right] & =\kappa^{2} \quad \sum_{d \in N} P_{t x, d}^{2} e^{2\left(\beta^{2} \sigma^{2}\right)} L\left(r_{i d}, r_{i o}\right)^{2}\left\{g_{1}\left(\frac{r_{i d}}{r_{i o}}\right)-f_{1}^{2}\left(\frac{r_{i d}}{r_{i o}}\right)\right\} U_{d} \\
& +\kappa^{2} \text { Bll } \sum^{2} \sum_{d \in M} P_{t x, d}^{2} e^{2\left(\beta^{2} \sigma^{2}\right)} L\left(r_{i d}, r_{i o}\right)^{2}\left\{g_{2}\left(\frac{r_{i d}}{r_{i o}}\right)-f_{2}^{2}\left(\frac{r_{i d}}{r_{i o}}\right)\right\} U_{d}
\end{aligned}
$$

Where

$$
\begin{aligned}
& g_{1}\left(\frac{r_{i d}}{r_{i o}}\right)=Q\left[2 \beta \sigma+\frac{10 \log _{10}\left\{L\left(r_{i d}, r_{i o}\right)\right\}}{\sigma}\right] \\
& f_{1}\left(\frac{r_{i d}}{r_{i o}}\right)=Q\left[\beta \sigma+\frac{10 \log _{10}\left\{L\left(r_{i d}, r_{i o}\right)\right\}}{\sigma}\right] \\
& g_{2}\left(\frac{r_{i d}}{r_{i o}}\right)=Q\left[2 \beta \sigma+\frac{10 \log _{10}\left\{B l l * L\left(r_{i d}, r_{i o}\right)\right\}}{\sigma}\right] \\
& f_{2}\left(\frac{r_{i d}}{r_{i o}}\right)=Q\left[\beta \sigma+\frac{10 \log _{10}\left\{B l l * L\left(r_{i d}, r_{i o}\right)\right\}}{\sigma}\right]
\end{aligned}
$$

The effect of the adjacent channel Interference (ACI) presented by ACIR (Adjacent Channel Interference Ratio) has been treated as follows:

If the leakage signal that reaches the user under consideration is transmitted via the main lobe of the base station antenna, Bll is changed by ACIR in equations (15, 20, 23 and 24).

If the leakage signal that reaches the user under consideration is transmitted via the back lobe of the base station antenna, Bll is changed by Bll*ACIR in equations $(15,20,23$ and 24).

The value of the total interference and total variance of the interference are given as: 


$$
\begin{aligned}
& E\left[I_{t}\right]=E\left[I_{c c}\right]+E\left[I_{a c}\right] \\
& \operatorname{var}\left[I_{t}\right]=\operatorname{var}\left[I_{c c}\right]+\operatorname{var}\left[I_{a c}\right]
\end{aligned}
$$

Finally, for a given availability $\alpha$ (usually is $95 \%$ to $99 \%$ ), the average Signal to Interference plus Noise ratio SINR per tone is given by:

$$
\text { SINR }=\frac{\frac{P_{r x}}{N_{\text {tones }}}}{\frac{\text { Noise }}{N_{\text {tones }}}+\frac{\text { Total Interference }}{N_{\text {tones }}}}
$$

which can be written as:

$$
\operatorname{SINR}=\frac{P_{r x}}{P_{N}+I C I+E\left[I_{t}\right]+Q^{-1}(\alpha) \sqrt{\operatorname{var}\left[I_{t}\right]}}
$$

Where $\mathrm{N}_{\text {tones }}$ is the number of LTE subcarriers, $\mathrm{P}_{\mathrm{N}}$ is the thermal noise of the entire channel band and ICI is the inter-carriers interference due to the movement of the user (Doppler effect causing frequency offset) and It is the total interference due to the cochannel and adjacent channel interference.

\section{NUMERICAL RESULTS}

Using the results of Section 3, some numerical results will be given. For our calculations we assume the following values. The inter-sites correlation coefficient $C_{\mathrm{do}}=0.5, \mathrm{n}_{1}=2, \mathrm{n}_{2}=4, \sigma_{1}=3 \mathrm{~dB}, \sigma_{2}=6$ $\mathrm{dB}, \mathrm{R}_{\mathrm{b}}=250 \mathrm{~m}, \mathrm{R}=1000 \mathrm{~m}$, and availability of $99 \%$ unless other values are mentioned. Also we assume that the base station transmitted power to each one of the two directions of the microcell is 2 $\mathrm{W}$, the mobile receiver noise figure is $7 \mathrm{~dB}$, and the frequency of operation is $2.6 \mathrm{GHz}$. The LTE bandwidth is assumed to be $10 \mathrm{MHz}$ with 600 subcarriers. The inter-carrier interference (ICI) has been calculated assuming a user velocity of $120 \mathrm{Km} / \mathrm{hr}$ [14]. The antenna used in each sector is assumed to have a gain of $12 \mathrm{~dB}$ (with $3 \mathrm{~dB}$ beam width of $42^{\circ} * 42^{\circ}$ ) and a front to back level of 20 $\mathrm{dB}$. ACIR of $-30 \mathrm{~dB}$ is assumed.

Table 1 shows the modulations schemes considered and the SNIR necessary to support them. Each modulation scheme consists of the type of modulation (for example, 64QAM) and the code rate (for example, 0.64).

Table1. Modulation schemes and their associated SINR.

\begin{tabular}{|c|c|c|}
\hline Order & Modulation scheme & SNIR (dB) \\
\hline 0 & No service & $<-3.4$ \\
\hline 1 & QPSK 0.17 & -3.4 \\
\hline 2 & QPSK 0.23 & -2.3 \\
\hline 3 & QPSK 0.29 & -1.4 \\
\hline 4 & QPSK 0.36 & $-\mathbf{0 . 4}$ \\
\hline 5 & QPSK 0.45 & 0.8 \\
\hline 6 & QPSK 0.55 & 2.7 \\
\hline 7 & QPSK 0.64 & 5.3 \\
\hline 8 & 16QAM 0.5 & 6.8 \\
\hline 9 & 16QAM 0.55 & 7.5 \\
\hline 10 & 16QAM 0.62 & $\mathbf{8 . 5}$ \\
\hline 11 & 16QAM 0.72 & 10.0 \\
\hline 12 & 16QAM 0.80 & 11.4 \\
\hline 13 & 64QAM 0.64 & 14.0 \\
\hline 15 & 64QAM 0.68 & 14.5 \\
\hline 16 & 64QAM 0.78 & 15.8 \\
\hline 17 & 64QAM 0.82 & 17.1 \\
\hline
\end{tabular}

We will study the LTE performance assuming a frequency reuse factor of 2 . 
Firstly we will present the case when the car is moving toward the transmitting antenna $\left(\mathrm{L}_{\text {extra }}\right.$ from left side $=0 \mathrm{~dB}, \mathrm{~L}_{\text {extra }}$ from right side $=10 \mathrm{~dB}$ ).

Fig. 3 shows the SINR as a function of the distance between the base station and the LTE mobile users. It can be noticed that the SINR is $28.94 \mathrm{~dB}$ for the LTE user at $100 \mathrm{~m}$ from the base station. At the sector border it falls to $9.78 \mathrm{~dB}$.
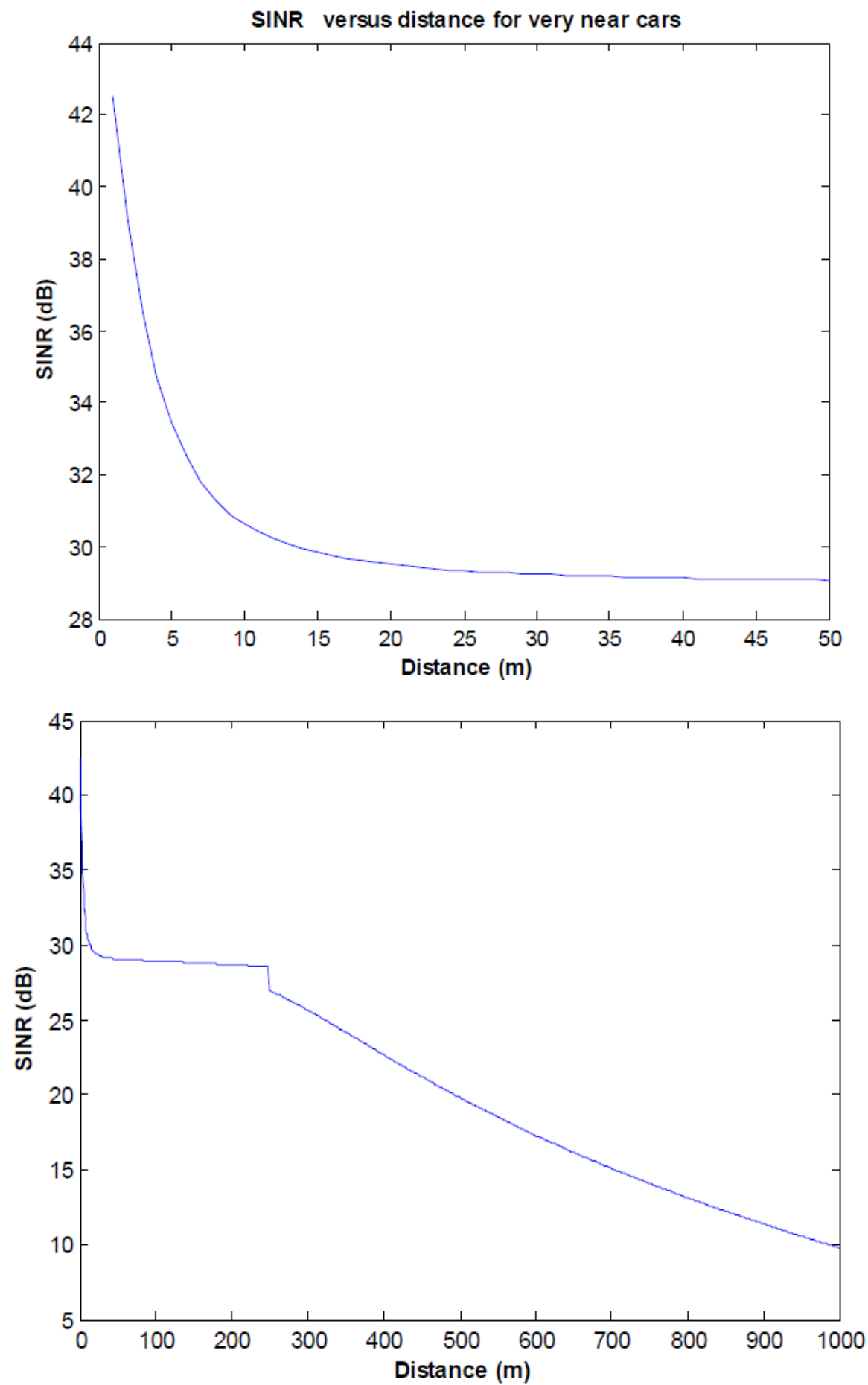

Fig3. SINR as a function of the LTE user distance from the base station when the car is moving toward the transmitting antenna.

The rapid change of SINR for users in cars very near to the base station is due to the rapid change of the Doppler frequency (due to the change of the angle between the base station antenna and velocity vector) and the effect of the vertical and horizontal radiation pattern of the base station directive antenna. We have to mention that, up to the $\mathrm{R}_{\mathrm{b}}$ distance the most effective factor that limits the SINR is the inter-carrier interference. For a distance higher than $\mathrm{R}_{\mathrm{b}}$, the noise power and the co-channel interference will also affect the SINR value. 
Fig. 4 shows the bit rate of the LTE user as a function of the distance between the base station and the LTE user. For a small distance between them, the bit rate reaches value of $49.14 \mathrm{Mbps}$. At the sector border, the bit rate falls to $22.32 \mathrm{Mbps}$. The average bit rate of this direction of the sector is 41.65 Mbps.

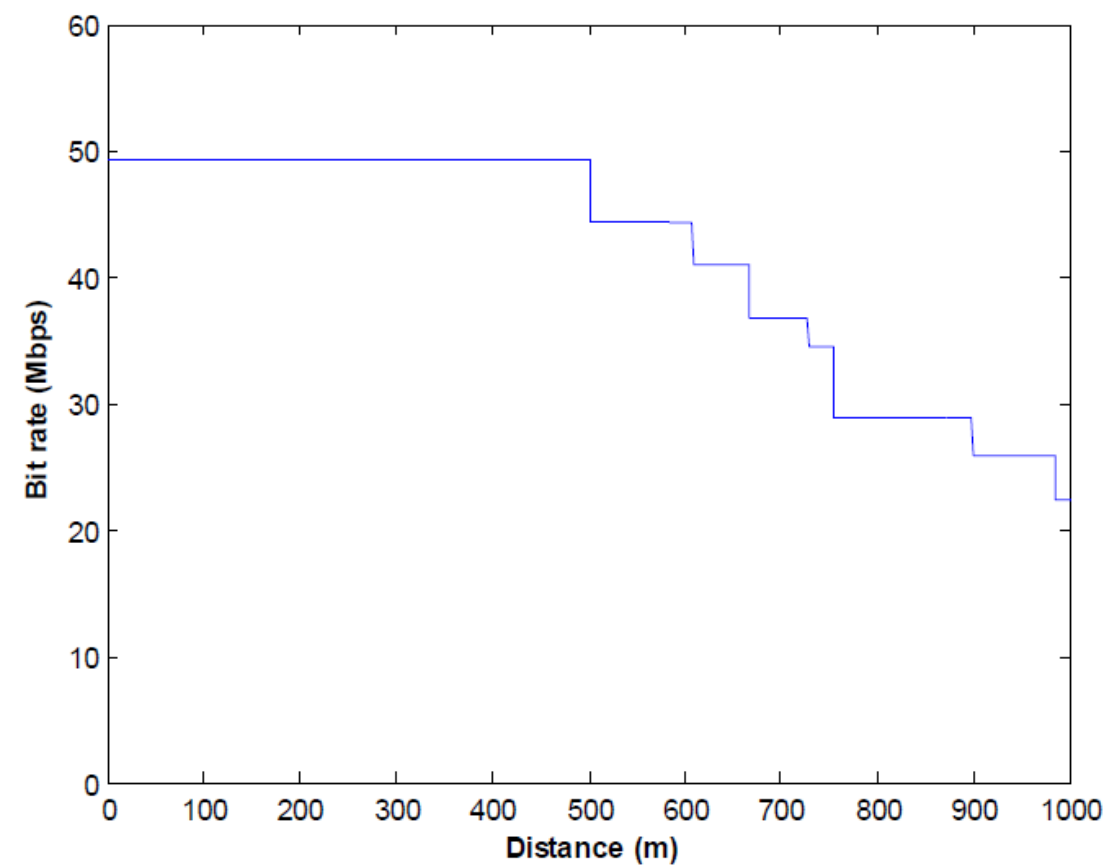

Fig4. Data rate of the LTE user as a function of the distance from the base station when the car is moving toward the transmitting antenna.

From Figures 3 and 4, it can be noticed that SINR near to the base station is high enough to support other higher modulations outside the standard.

Now we will present the case when the car is moving far away from the transmitting antenna $\left(\mathrm{L}_{\text {extra }}\right.$ from left side $=10 \mathrm{~dB}, \mathrm{~L}_{\text {extra }}$ from right side $=0 \mathrm{~dB}$ ).

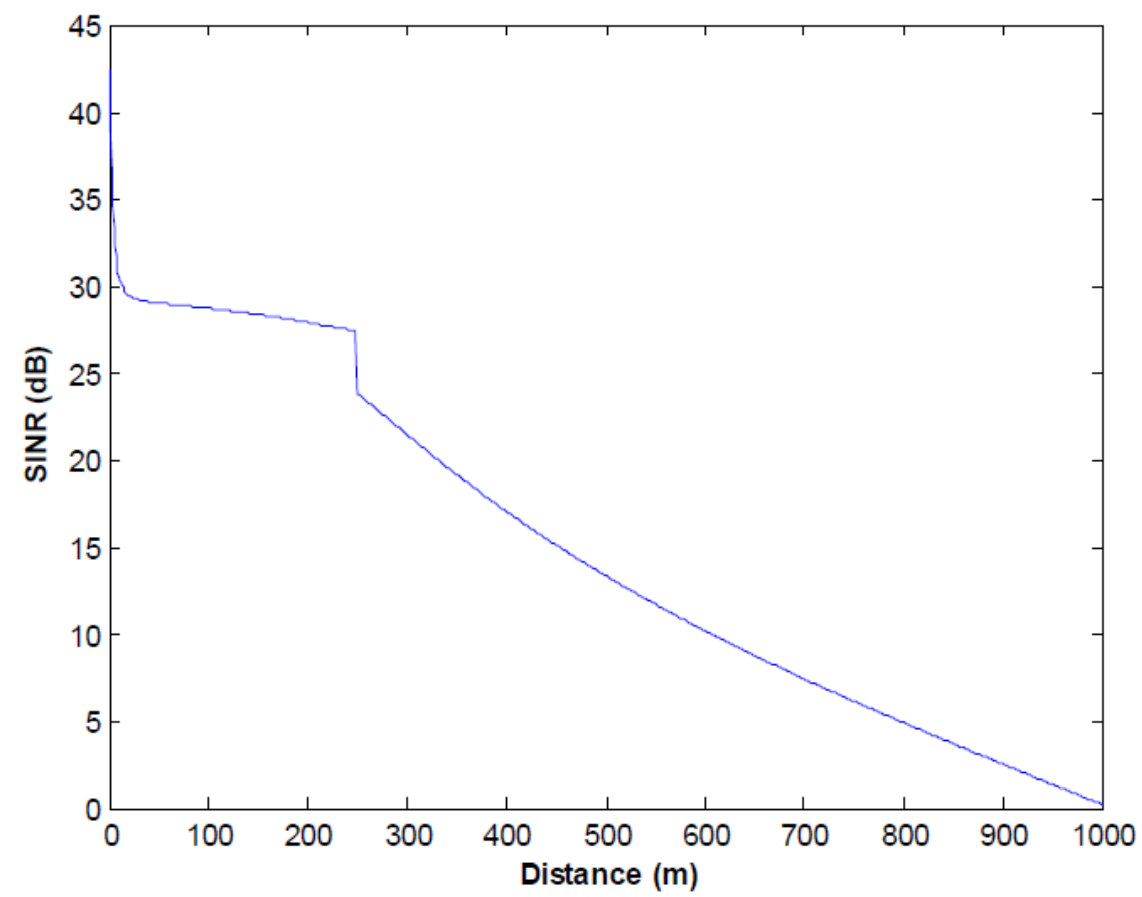

Fig5. SINR as a function of the LTE user distance from the base station when the car is moving far away from the transmitting antenna.

Fig. 5 shows the SINR as a function of the distance between the base station and the LTE mobile users. It can be noticed that the SINR is $28.73 \mathrm{~dB}$ for the LTE user at $100 \mathrm{~m}$ from the base station. At the sector border it falls to $0.22 \mathrm{~dB}$. 


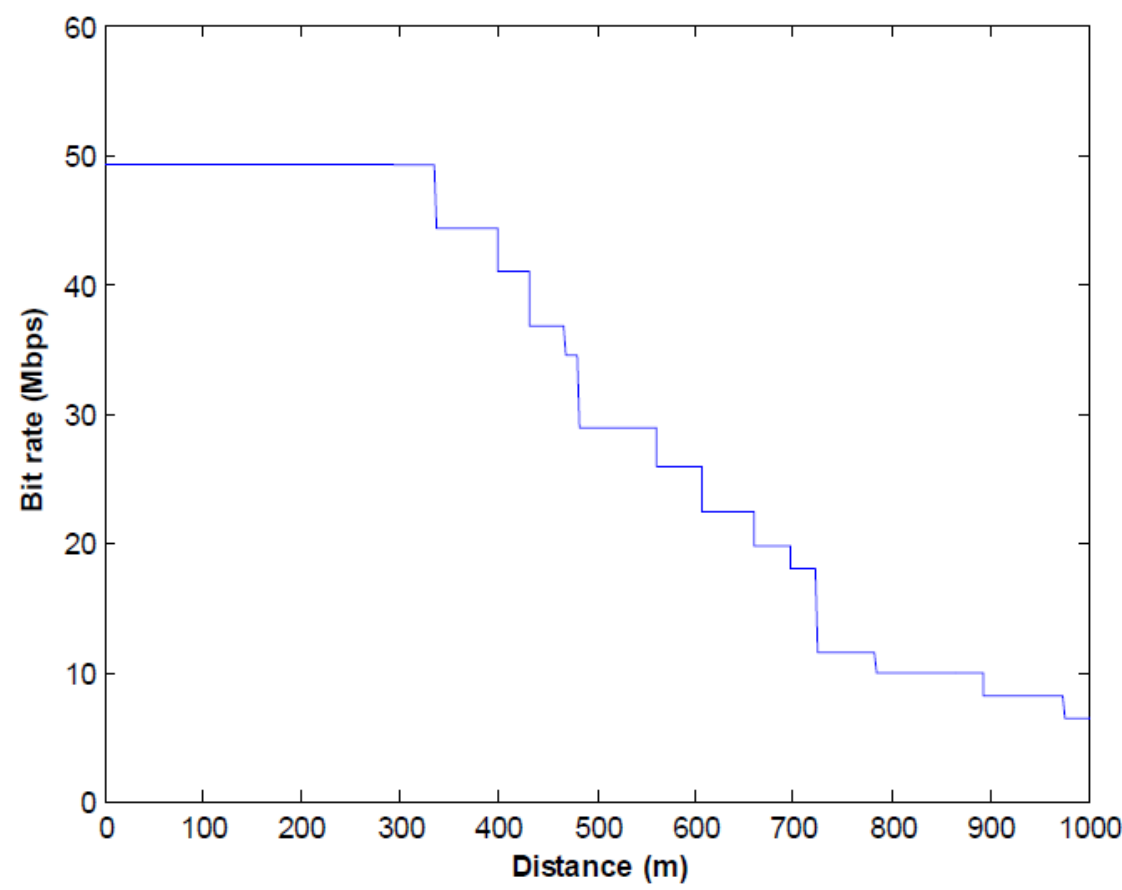

Fig6. Data rate of the LTE user as a function of the distance from the base station when the car is moving far away from the transmitting antenna.

Fig. 6 shows the bit rate of the LTE user as a function of the distance between the base station and the LTE user. For a small distance between them, the bit rate reaches value of $49.14 \mathrm{Mbps}$. At the sector border, the bit rate falls to $6.48 \mathrm{Mbps}$. The average bit rate of this direction of the sector is 30.90 Mbps.

The average bit rate of the all of the sector is 36.27 Mbps.

Now we will present the case when the car is moving far away from the transmitting antenna for $\mathrm{R}=$ $1500 \mathrm{~m}$.

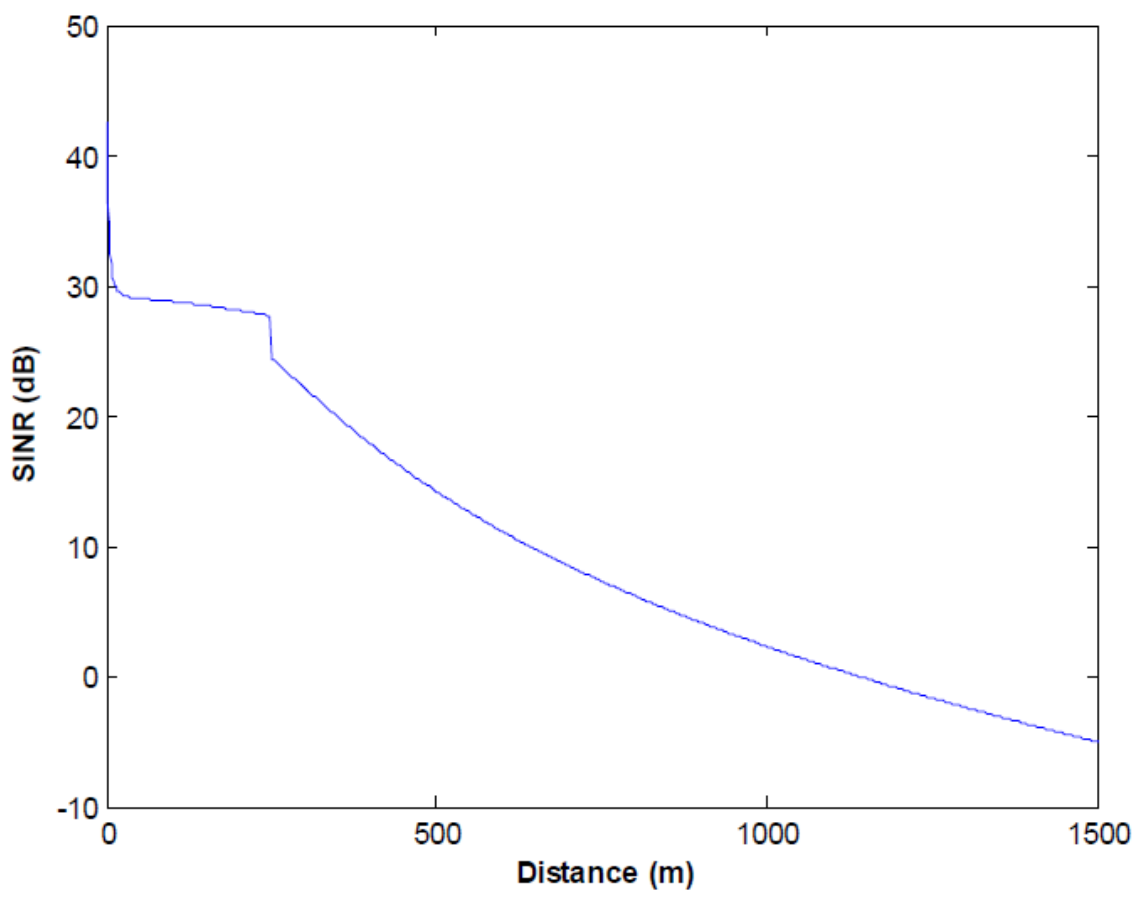

Fig7. SINR as a function of the LTE user distance from the base station when the car is moving far away from the transmitting antenna for $R=1500 \mathrm{~m}$.

Fig. 7 shows the SINR as a function of the distance between the base station and the LTE mobile users. At the sector border it falls to $-5.03 \mathrm{~dB}$. 


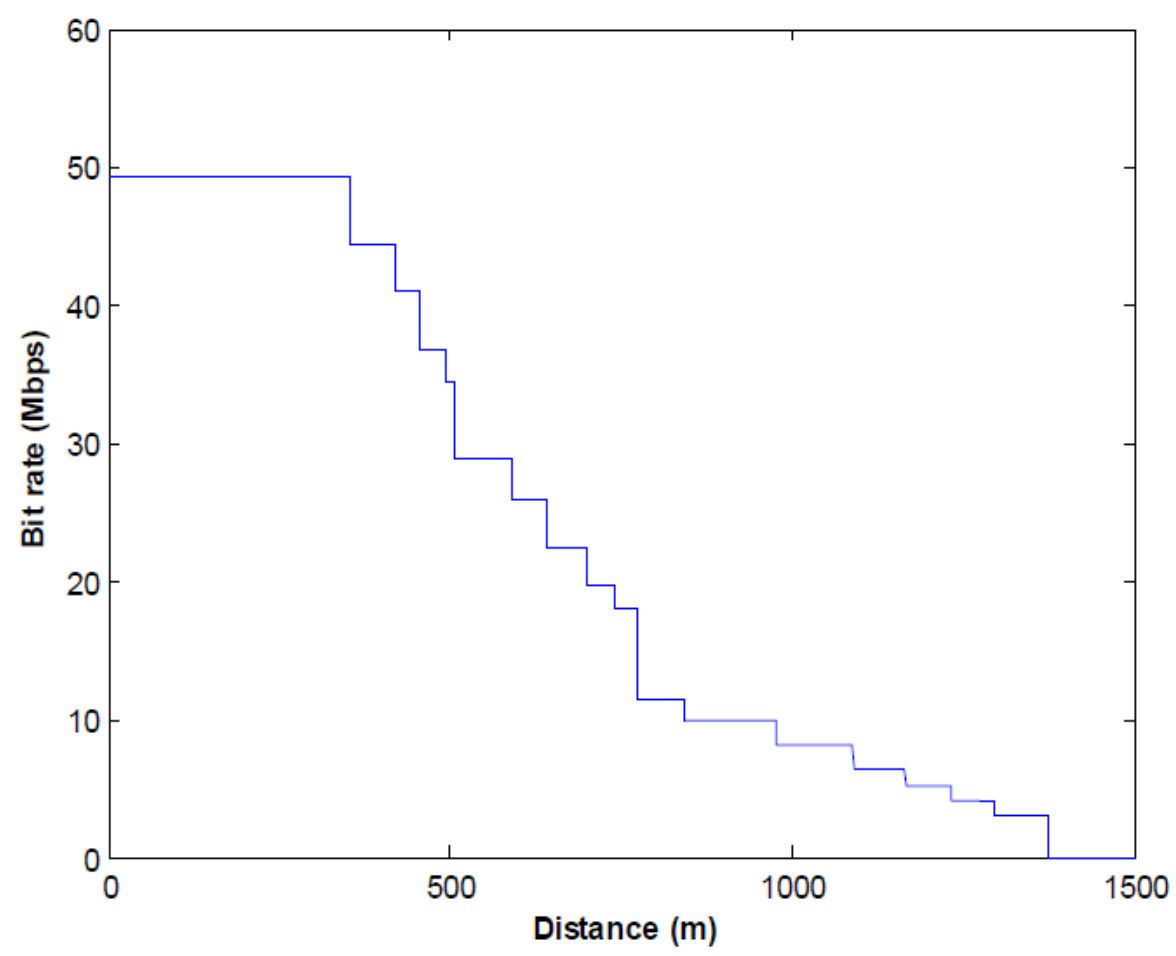

Fig8. Data rate of the LTE user as a function of the distance from the base station when the car is moving far away from the transmitting antenna for $R=1500 \mathrm{~m}$.

Fig. 8 shows the bit rate of the LTE user as a function of the distance between the base station and the LTE user. For a small distance between them, the bit rate reaches value of $49.14 \mathrm{Mbps}$. At the sector border, the bit rate falls to $0 \mathrm{Mbps}$. For a distance of $1375 \mathrm{~m}$, no service is supported. Thus it is not acceptable to have $\mathrm{R}=1500 \mathrm{~m}$ when the transmitted power is $2 \mathrm{~W}$. Now we will present the case when the car is moving far away from the transmitting antenna for $\mathrm{R}=1500 \mathrm{~m}$ and a transmitted power of $4 \mathrm{~W}$.

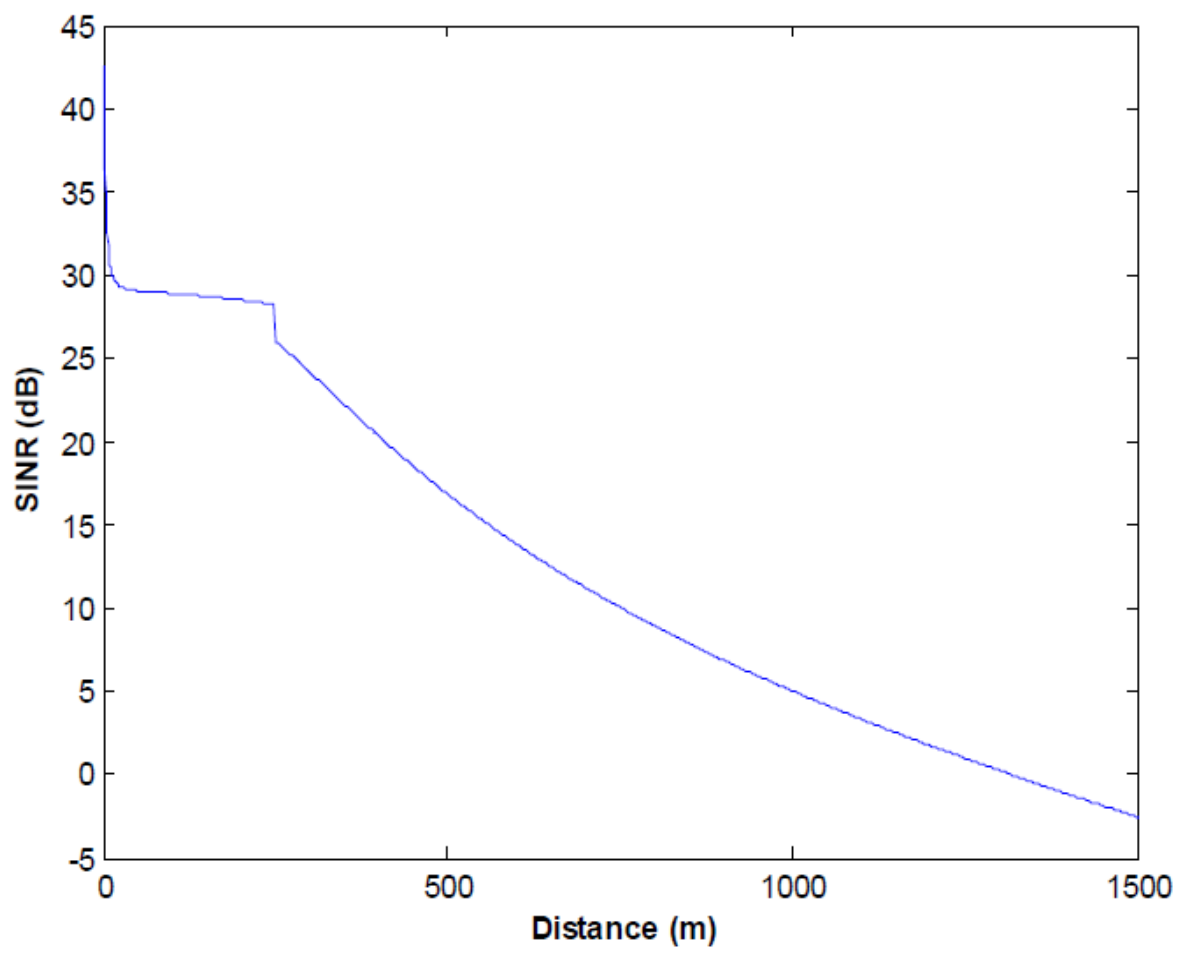

Fig9. SINR as a function of the LTE user distance from the base station when the car is moving far away from the transmitting antenna for $R=1500 \mathrm{~m}$ and a transmitted power of $4 \mathrm{~W}$.

Fig. 9 shows the SINR as a function of the distance between the base station and the LTE mobile users. At the sector border it falls to $-2.54 \mathrm{~dB}$.

International Journal of Innovative Research in Electronics and Communications (IJIREC) $\quad$ Page | 18 


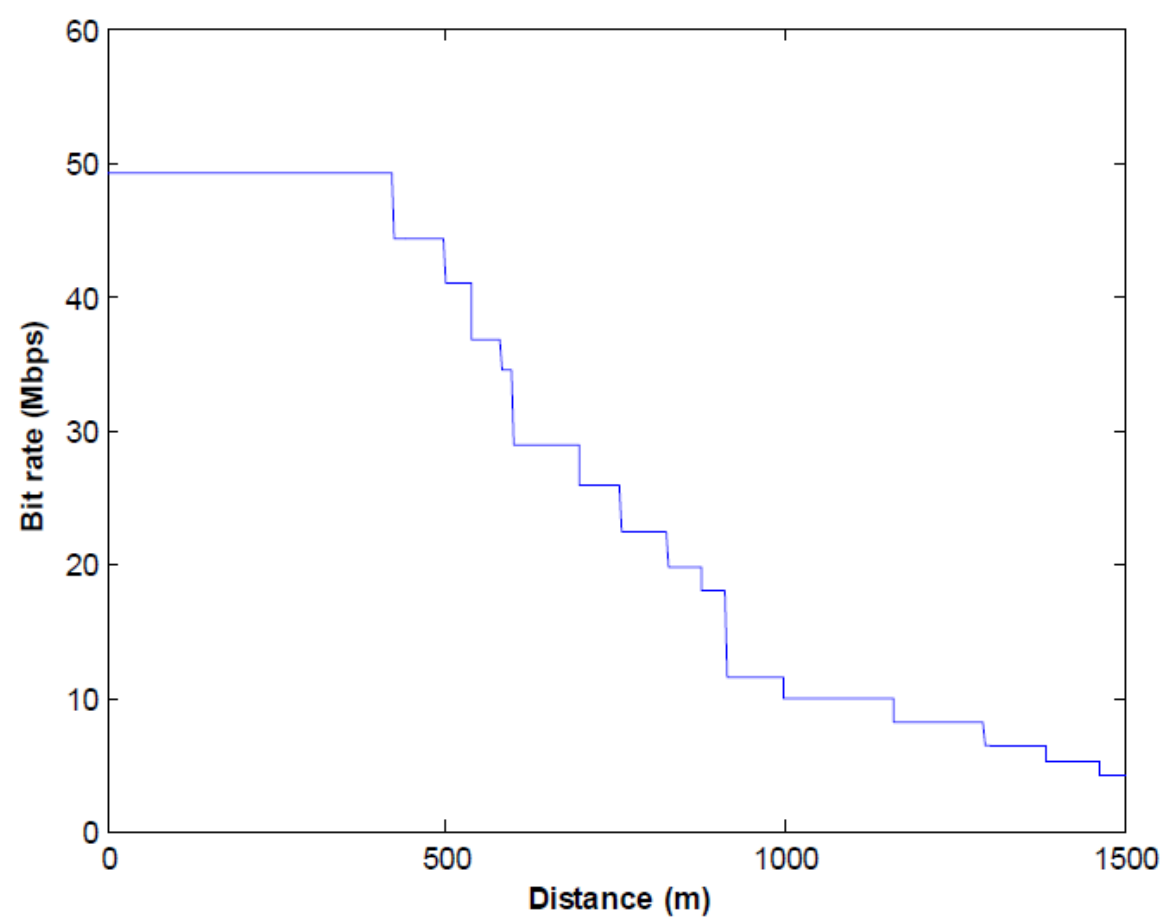

Fig10. Data rate of the LTE user as a function of the distance from the base station when the car is moving far away from the transmitting antenna for $R=1500 \mathrm{~m}$ and a transmitted power of $4 \mathrm{~W}$.

Fig. 10 shows the bit rate of the LTE user as a function of the distance between the base station and the LTE user. For a small distance between them, the bit rate reaches value of $49.14 \mathrm{Mbps}$. At the sector border, the bit rate falls to $3.06 \mathrm{Mbps}$. The average bit rate of this direction of the sector is 26.58 Mbps.

The maximum sector range with a transmitted power of $4 \mathrm{~W}$ is $1637 \mathrm{~m}$.

For a receiver noise figure of $6 \mathrm{~dB}$, the maximum sector range that can be supported with a transmitting power of $4 \mathrm{~W}$ is $1716 \mathrm{~m}$.

When $2 * 2$ MIMO is applied, the bit rate can be doubled [5]. Fig. 11 shows the data rate of the LTE user as a function of the distance from the base station when the car is moving toward the transmitting antenna using a $2 \times 2 \mathrm{MIMO}$. The maximum bit rate is $98.28 \mathrm{Mbps}$. At sector edge the bit rate reduced to $44.64 \mathrm{Mbps}$.

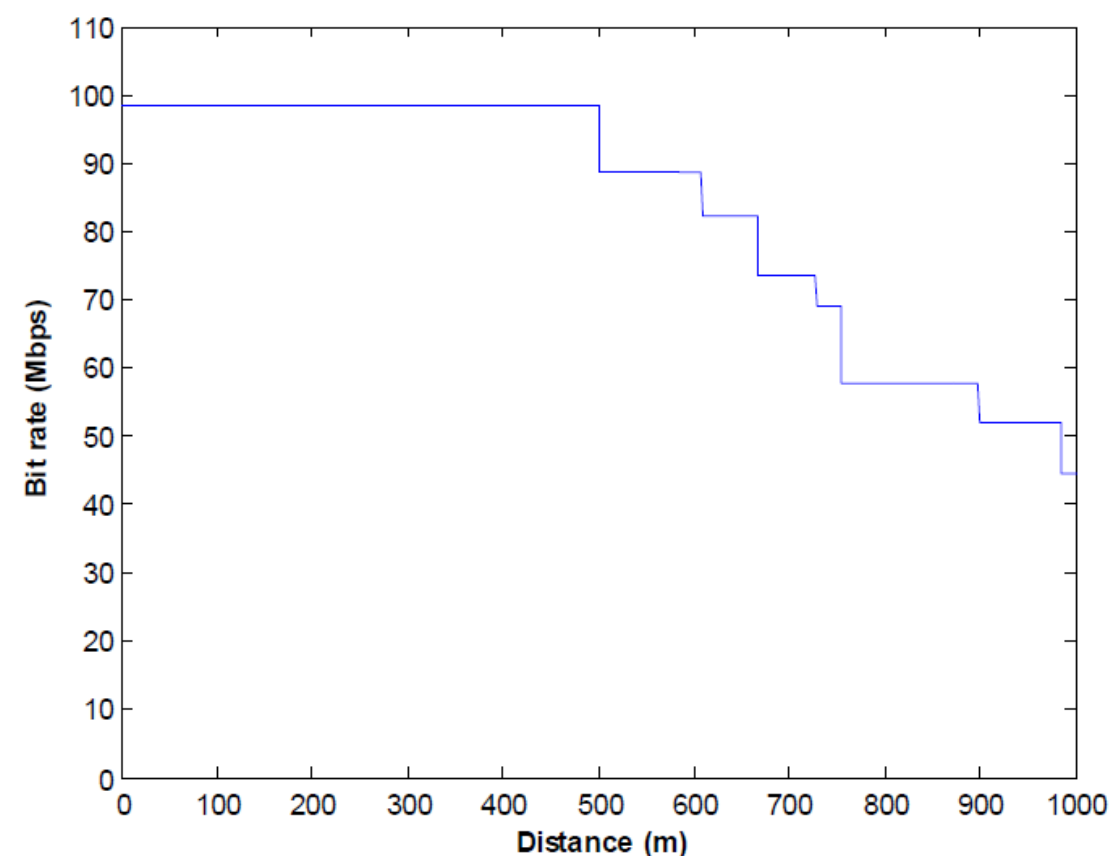

Fig11. Data rate of the LTE user as a function of the distance from the base station when the car is moving toward the transmitting antenna when $2 \times 2$ MIMO is used. 
Table2. Maximum sector range versus the transmitted power for the $2600 \mathrm{MHz}$ working band and $10 \mathrm{MHz}$ bandwidth for $R_{b}=250 \mathrm{~m}$.

\begin{tabular}{|c|c|}
\hline Sector transmitted power $(\mathbf{W})$ & Maximum sector range (m) \\
\hline 1 & 1145 \\
\hline 2 & 1356 \\
\hline 3 & 1488 \\
\hline 4 & 1609 \\
\hline
\end{tabular}

Table3. Maximum sector range versus the transmitted power for the $800 \mathrm{MHz}$ working band and $10 \mathrm{MHz}$ bandwidth for $R_{b}=250 \mathrm{~m}$.

\begin{tabular}{|c|c|}
\hline Sector transmitted power $(\mathbf{W})$ & Maximum sector range (m) \\
\hline 1 & 2052 \\
\hline 2 & 2428 \\
\hline 3 & 2709 \\
\hline 4 & 2883 \\
\hline
\end{tabular}

Here base station antenna should be at a height of 30 meter. Comparing the results of Tables 2 and 3 , it can be noticed that the maximum sector range in Table 3 is almost $80 \%$ higher than its value in Table 2.

Table 4: Maximum sector range versus the transmitted power for the $800 \mathrm{MHz}$ working band and $10 \mathrm{MHz}$ bandwidth for $R_{b}=80 \mathrm{~m}$.

\begin{tabular}{|c|c|}
\hline Sector transmitted power $(\mathbf{W})$ & Maximum sector range (m) \\
\hline 1 & 1163 \\
\hline 2 & 1377 \\
\hline 3 & 1516 \\
\hline 4 & 1631 \\
\hline
\end{tabular}

Comparing the results of Tables 2 and 4, it can be noticed that the maximum sector range in Table 3 is little bit higher than its value in Table 2 . With $\mathrm{R}_{\mathrm{b}}$ of 77 meter, results will be almost equal.

If a channel bandwidth of $20 \mathrm{MHz}$ is used, the peak download bit rate will be $98.28 \mathrm{Mbps}$.

For lower value of $\sigma_{2}$, the maximum supported range will be higher than the up given ranges. Also for lower availability $\alpha$, the maximum supported range will be higher than the up given ranges. For lower $\mathrm{R}_{\mathrm{b}}$, the maximum supported range will be lower.

Since a directive antenna is used in the base station and an almost LOS ray also exists between the base station and LTE user then Rice fading from nearby objects (if they exists) is expected.

Let us now study the effect of small scale fading assuming that Rice fading takes place.

Firstly, let us study the case when $\mathrm{K}$ is 10 . Fig. 12 shows the data rate of the LTE user as a function of the distance from the base station when the car is moving far away from the transmitting antenna with Rice fading when $K=10$. It can be seen that there is a point at which there is not any LTE service.

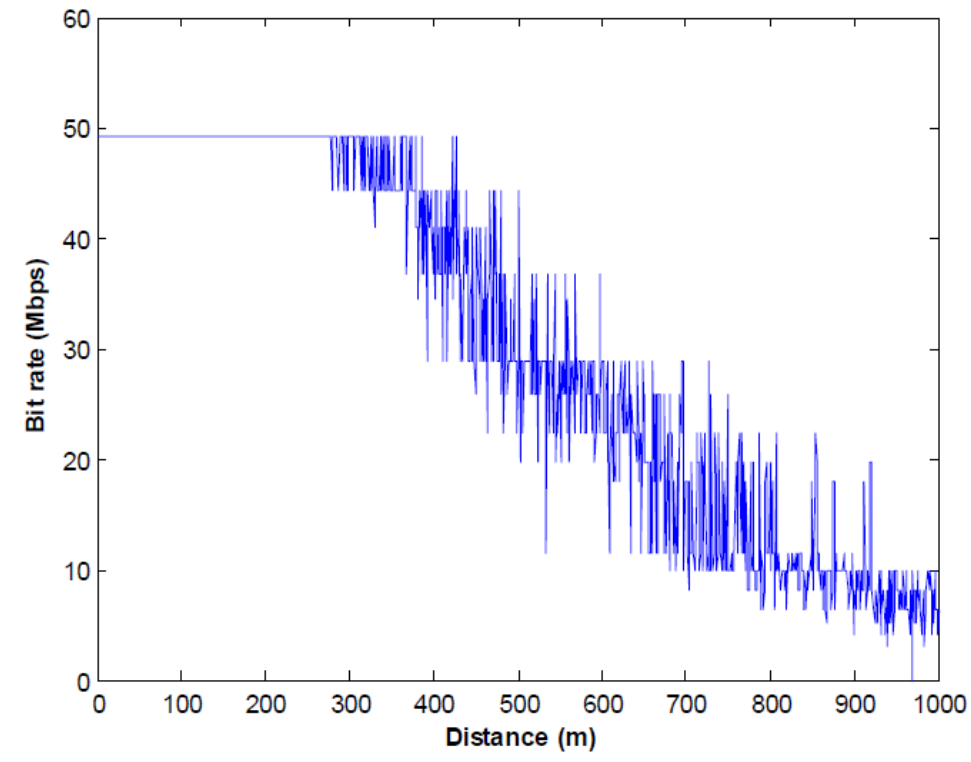

Fig12. Data rate of the LTE user as a function of the distance from the base station when the car is moving far away from the transmitting antenna with Rice fading when $K=10$.

International Journal of Innovative Research in Electronics and Communications (IJIREC) $\quad$ Page $\mid 20$ 
Secondly, let us study the case when $\mathrm{K}$ is 5 . Fig. 13 shows the data rate of the LTE user as a function of the distance from the base station when the car is moving far away from the transmitting antenna with Rice fading when $K=5$. It can be seen that there are many point at which there is not any LTE service.

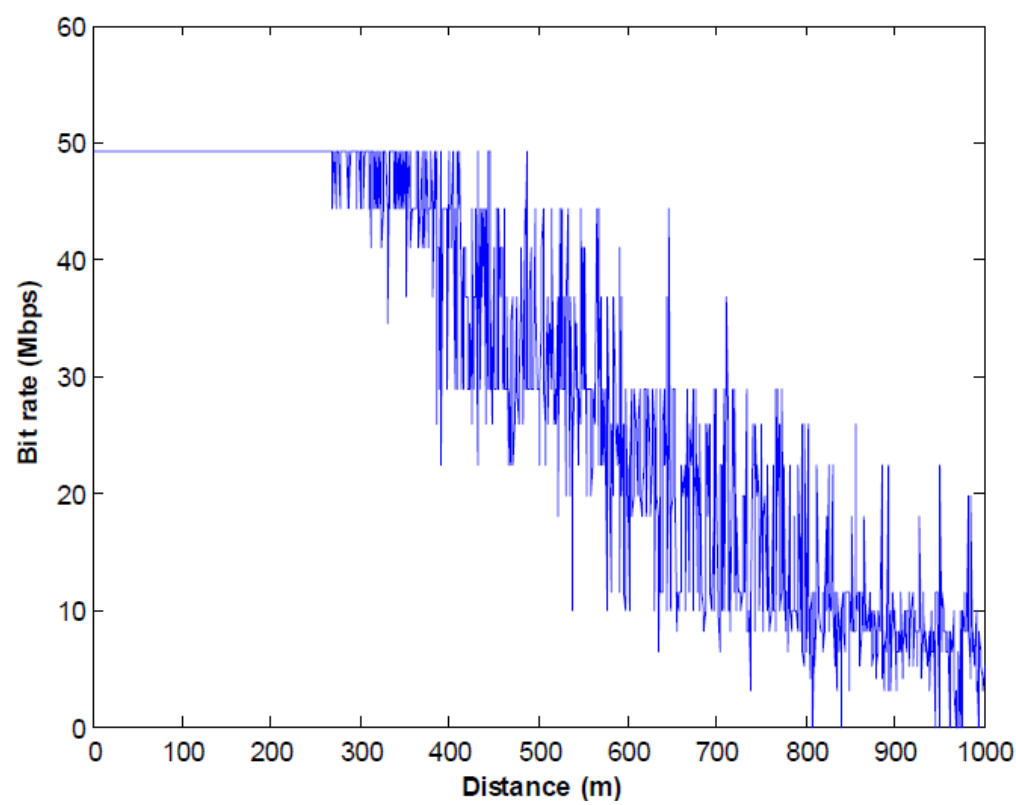

Fig13. Data rate of the LTE user as a function of the distance from the base station when the car is moving far away from the transmitting antenna with Rice fading when $K=5$.

To solve this, the transmitted power, the break point distance and the base station antenna gain should be increased. The break point distance can be increased increasing the base station antenna height.

Fig. 14 shows the data rate of the LTE user as a function of the distance from the base station when the car is moving far away from the transmitting antenna with Rice fading when $K=5, R_{b}=500 \mathrm{~m}$, $\mathrm{G}_{\mathrm{tx}}=14 \mathrm{~dB}$ and $\mathrm{P}_{\mathrm{tx}}=4 \mathrm{~W}$. Here the points without LTE service have been disappeared.

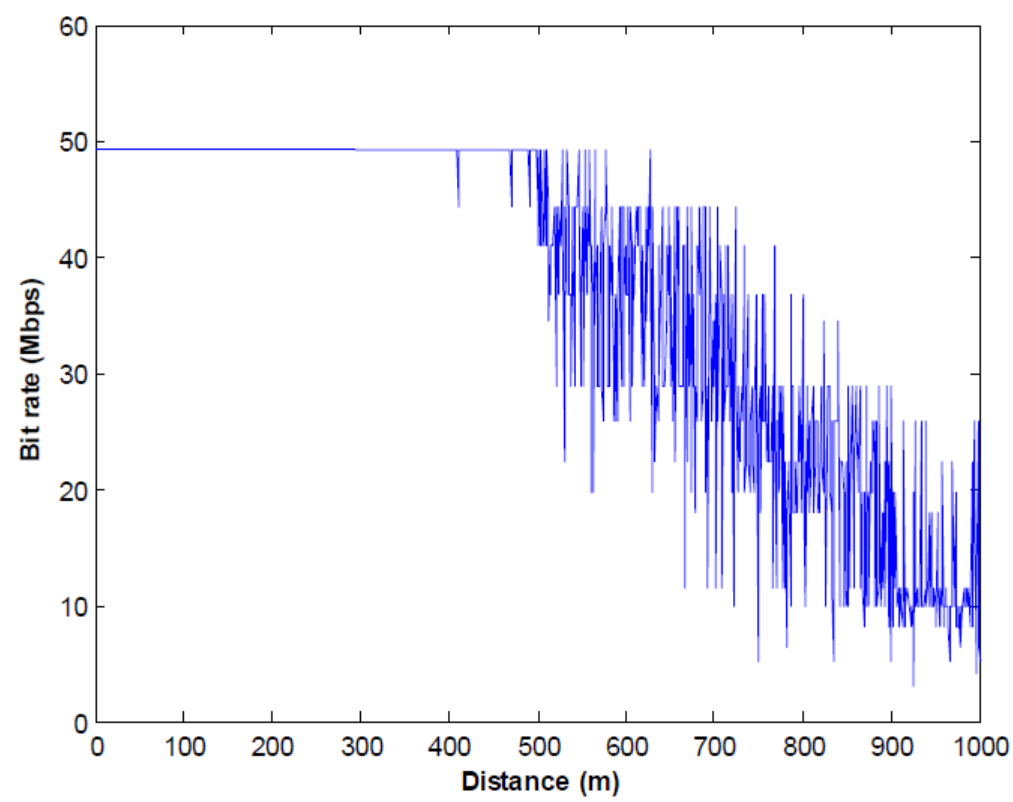

Fig14. Data rate of the LTE user as a function of the distance from the base station when the car is moving far away from the transmitting antenna with Rice fading when $K=5, R_{b}=500 \mathrm{~m}, G_{t x}=14 \mathrm{~dB}$ and $P_{t x}=4 \mathrm{~W}$.

In Time Division Duplex (TDD) mode of operation, LTE use the same channel for uplink and downlink transmission. Possible Downlink time to (Downlink + Uplink) time could be $40 \%$ to $90 \%$. To mitigate the effect of multipath, guard time is used. This will reduce the effective downlink bit rate. For the above given reasons, downlink effective bit rate could be $28 \%$ to $66 \%$ of the above given values of bit rate. 
Using a frequency reuse of 3, the mean bit rate of the sector increases only $3 \%$ with the cost of using $150 \%$ bandwidth. Thus it is better to use the frequency reuse of 2 .

In appendix A, the base station antenna gain as a function of the user distance from the base station is shown by Fig. A1. The Doppler frequency as a function of the user distance from the base station is depicted in Fig. A2. At a distance of $400 \mathrm{~m}$ form the base station, the base station antenna gain and the Doppler frequency almost reach their final values at very high distance.

\section{CONCLUSiOnS}

In this work, the performance of LTE systems (SINR, modulation schemes and downlink bit rate) for cigar-shaped microcells at highways is studied. The two-slope propagation loss model has been used to calculate the signal to interference plus noise ratio taking into account the expected value and the variance of the interference. A model of ten cigar-shaped microcells is used in the LTE performance analysis. For the frequency band of $2.6 \mathrm{GHz}$ with $10 \mathrm{MHz}$ bandwidth, the base station transmitted power should be $2 \mathrm{~W}$ to get a sector range of $1356 \mathrm{~m}$ meanwhile it should be $3.1 \mathrm{~W}$ to get $1500 \mathrm{~m}$ sector range. For the $800 \mathrm{MHz}$ frequency band, maximum range of 2909 can be got with a transmitted power $4 \mathrm{~W}$ when the break point distance $\mathrm{R}_{\mathrm{B}}$ is maintained at $250 \mathrm{~m}$. With a frequency reuse of 2, a sector bit rate up to $41.65 \mathrm{Mbps}$ can be got with a $10 \mathrm{MHz}$ bandwidth meanwhile for a frequency reuse of 3, the mean bit rate of the sector will be $42.9 \mathrm{Mbps}$ with the cost of using $150 \%$ bandwidth. Small scale fading affects the SINR of the LTE user and consequently the downlink bit rate.

\section{Appendix A}

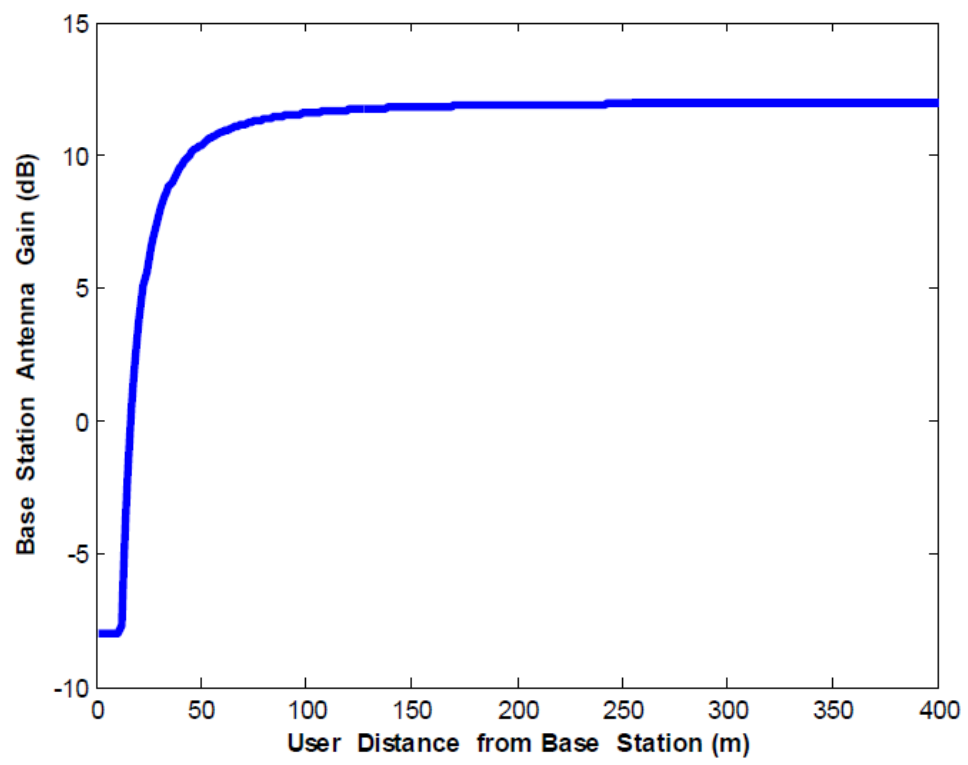

FigA1. Base station antenna gain as a function of user distance from it.

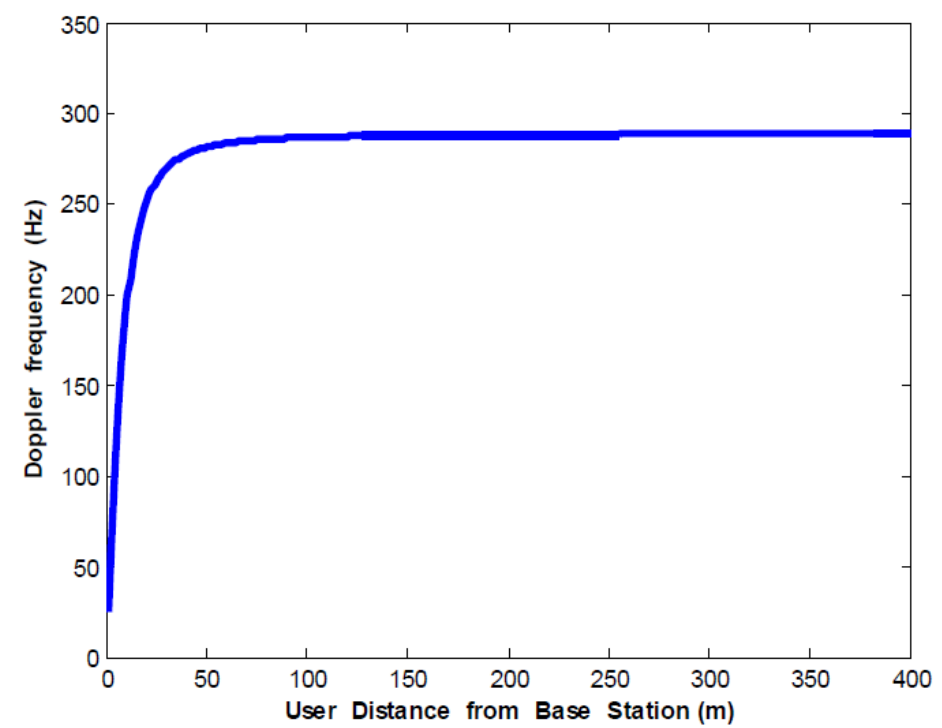

FigA2. Doppler frequency as a function of user distance from the base station $(v=120 \mathrm{Km} / \mathrm{hr})$. 


\section{REFERENCES}

[1] Stefania Sesia, Issam Toufik, Matthew Baker LTE: The UMTS Long Term Evolution: From Theory to Practice, John Wiley \& Sons, 2 Edition, 2011.

[2] Mogensen,P. , Wei Na ; Kovacs, I.Z. ; Frederiksen, F. ; Pokhariyal, A. ; Pedersen, K.I. ; Kolding, T. ; Hugl, K. ; Kuusela, M, "LTE Capacity Compared to the Shannon Bound", Vehicular Technology Conference, 2007. VTC2007-Spring., pp. 1234-1238.

[3] Niyato, D., Lu, X., \&Wang, P. “Adaptive power management for wireless base stations in a smart grid environment", IEEE Wireless Communications, 19(6), 44-51, 2012.

[4] Ericsson corporation report. (2013). Ericsson mobility report on the pulse of the networked society. Ericsson Corporation. http://www.ericsson.com/res/docs/2013/ericsson-mobility-report-june-2013.pdf.

[5] Sonia Rathi, Nisha Malik, Nidhi Chahal, Sukhvinder Malik, "Throughput for TDD and FDD 4 G LTE Systems", International Journal of Innovative Technology and Exploring Engineering (IJITEE), pp. 73-77, May 2014.

[6] Fahimeh Rezaei, Michael Hempel, Hamid Sharif, "LTE PHY Performance Analysis under 3GPP Standards Parameters”, CMAD Workshop, pp. 102-106, 2011.

[7] Seungwook Min and Henry L. Bertoni “ Effect of Path Loss Model on CDMA System Design for Highway Microcells “, 48 th VTC, Ottawa, Canada, pp 1009-1013, May 1998.

[8] B. Taha Ahmed, M. Calvo Ramón, L. Haro Ariet, "Capacity and Interference Statistics of Highways WCDMA Cigar-shaped Microcells (Uplink analysis)”, IEEE Communications Letters, Vol. 6, pp. 172-174, May 2002.

[9] B. Taha Ahmed, Miguel Calvo Ramón, Leandro Haro Ariet, "WCDMA Uplink Capacity and Interference Statistics of Highways Shaped Microcells with Imperfect Power Control and Finite Transmitted Power", Wireless Personal Communications, Vol. 43, No. 2, pp. 295-311, October 2007.

[10] B. Taha Ahmed, Miguel Calvo Ramón, and Leandro Haro Ariet, "WCDMA multiservice uplink capacity of highways cigar-shaped microcells", EURASIP Journal on Wireless Communications and Networking, Vol. 2007, pp. 1- 5, 2007.

[11] B. Taha Ahmed, Miguel Calvo Ramón, "WCDMA downlink capacity of cigar-shaped microcells using soft hand-over with SIR-based power control for over-ground train service", Computer Communications Journal, Vol. 31, pp. 88-94, Febrero 2008.

[12] B. Taha Ahmed, Miguel Calvo Ramón, "Infostations for Highway Cigar-Shaped Cells", Computer Communications Journal, Vol.32, No. 4, pp. 730-735, 4 March 2009.

[13] Ywh-Ren Tsai and Jin-Fu Chang, " Feasibility of Adding a Personal Communications Network to an Existing Fixed-service Microwave System“, IEEE Trans. Com., Vol. 44, No. 1, pp 76-83, Jan. 1996.

[14] K. A. Hamdi, "Exact SINR Analysis of Wireless OFDM in the Presence of Carrier Frequency Offset", IEEE Transactions on Wireless Communications, Vol. 9, No. 3, pp. 975-979, March 2010.

\section{AUTHOR'S BIOGRAPHY}

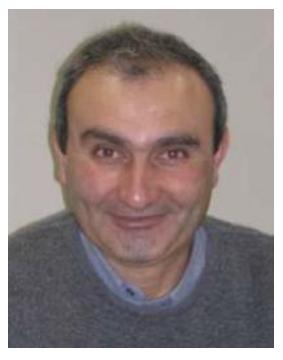

Bazil Taha Ahmed, was born in Mosul, Iraq, in 1960. He received the B.Sc. and M.Sc. degrees in Electronics and Telecommunication Engineering from the University of Mosul, in 1982 and 1985, respectively. He got the D. E. A. and the $\mathrm{Ph}$. D degree both in Telecommunication Engineering from the Polytechnic University of Madrid in 2001 and 2003 respectively. Now he is working as an Associate Professor at the Universidad Autonoma de Madrid. He has published more than 120 scientific journal and conference papers in the area of the electromagnetic propagation and Telecommunication systems.

Citation: Bazil Taha Ahmed. (2018) "LTE Downlink Performance of Cigar-Shaped Highways Microcells with and Without Small Scale Fading", International Journal of Innovative Research in Electronics and Communications (IJIREC), 5(2), pp 9-23. DOI: http://dx.doi. org/10.20431/2349-4050.0502002

Copyright: () 2018 Bazil Taha Ahmed, This is an open-access article distributed under the terms of the Creative Commons Attribution License, which permits unrestricted use, distribution, and reproduction in any medium, provided the original author and source are credited. 